Eduardo Navarro Stotz ${ }^{\mathrm{a}}$

Jose Augusto Pina ${ }^{\mathrm{a}}$

\section{Experiência operária e ciência na luta pela saúde e a emancipação social}

\author{
Working class experience and science in the struggle for health \\ and social emancipation
}

${ }^{a}$ Fundação Oswaldo Cruz. Escola Nacional de Saúde Pública. Rio de Janeiro, RJ, Brasil.

Contato:

Eduardo Navarro Stotz

E-mail:

stotz@ensp.fiocruz.br

Os autores declaram que o trabalho não foi subvencionado e que não há conflitos de interesses.

Os autores informam que o trabalho não é oriundo de dissertação ou tese.

Versão ampliada e revista de texto apresentado na mesa-redonda Lutas sociais, atuação sindical e saúde do trabalhador, como parte do evento científico Cesteh 30 anos, promovido pelo Centro de Estudos da Saúde do Trabalhador e Ecologia Humana (Cesteh), Escola Nacional de Saúde Pública (Ensp), Fundação Oswaldo Cruz (Fiocruz), realizado de 9 a 11 de dezembro de 2015.

Recebido: 30/11/2016

Revisado: 19/01/2017

Aprovado: 20/01/2017

\section{Resumo}

Este ensaio desenvolve uma reflexão acerca da relação entre experiência operária e ciência na luta pela saúde e a emancipação social como contribuição para o campo da Saúde Coletiva/Saúde do Trabalhador. Partimos desta questão - pode haver compatibilidade entre produção capitalista e saúde? - para assinalar, na primeira seção, a resposta majoritária oferecida pelo movimento sindical brasileiro na atualidade. Na segunda e terceira seções analisamos algumas obras referidas à experiência histórica do enfrentamento do capital pelos trabalhadores, especialmente na Itália nos anos 1960-1970, para pensar, respectivamente, nas respostas à questão proposta e na relação entre teoria e prática. Depois, discutimos as contribuições e os limites do Modelo Operário Italiano de luta pela saúde para, em seguida, recuperarmos deste legado o sentido de classe na relação entre ciência e experiência. Na sexta seção, apresentamos experiências de resistência dos trabalhadores brasileiros à exploração capitalista relacionadas à luta pela saúde, com o que retomamos a questão inicial. Destacamos, na problemática apontada, os sentidos que o direito à saúde e da saúde entendida como luta da classe trabalhadora passam a assumir no âmbito da produção do conhecimento e das ações em saúde.

Palavras-chave: ciência e experiência operária; saúde do trabalhador; capitalismo e saúde; Modelo Operário Italiano.

\begin{abstract}
As a contribution for the field of Collective Health/Workers' Health, this essay develops a reflection on the relationship between the working class experience and science in the struggle for health and social emancipation. We start with the question - Can capitalist production and health be compatible? - to point out, in the first part, the prevailing response offered nowadays by the Brazilian trade union movement. In the second and third sections, we analyze some studies referring to the historical experience of workers' confrontation to capital, especially in Italy in the 1960s-1970s, to think about both the answers to the proposed question and the theory and practice relationship. Then, we discuss the contributions and limits of the Italian worker's struggle for the Health Model. This legacy enables us to restore the meaning of class in the science and experience relationship. In the sixth part, we present experiences of the Brazilian workers' health struggle as resistance to capitalist exploitation, and we return to the initial question. We highlight, in the pointed out problematic, the meanings of "right to health" and of health, understood as working class struggle, acquired within the spheres of knowledge production and health actions.
\end{abstract}

Keywords: science and working class experience; workers' health; capitalism and health; Italian working class model. 


\section{Introdução}

\begin{abstract}
Entretanto, seremos ainda cientistas, se nos desligamos da multidão? Os movimentos dos corpos celestes se tornaram mais claros; mas os movimentos dos poderosos continuam imprevisíveis para os seus povos. A luta pela mensuração do céu foi ganha através da dúvida; e a credulidade da dona-de-casa romana fará que ela perca sempre de novo a sua luta pelo leite. A ciência, Sarti, está ligada às duas lutas. Enquanto tropeça dentro de sua bruma luminosa de superstições e afirmações antigas, ignorante demais para desenvolver plenamente as suas forças, a humanidade não será capaz de desenvolver as forças da natureza que vocês descobrem. Vocês trabalham para quê? Eu sustento que a única finalidade da ciência está em aliviar a canseira da existência humana. E se os cientistas, intimidados pela prepotência dos poderosos, acham que basta amontoar saber, por amor do saber, a ciência pode ser transformada em aleijão, e as suas novas máquinas serão novas aflições, nada mais. Com o tempo,

é possível que vocês descubram tudo o que haja por descobrir, e ainda assim o seu avanço há de ser apenas um avanço para longe da humanidade.
\end{abstract}

Bertolt Brecht, Vida de Galileu Galilei.

Este ensaio pretende desenvolver uma reflexão acerca da relação entre experiência operária e ciência na luta pela saúde e a emancipação social. Para isso, partimos de uma questão geral - pode haver compatibilidade entre produção capitalista e saúde? - para, imediatamente, propor um desdobramento das possíveis respostas à seguinte questão: qual a relação que podemos estabelecer entre ciência e experiência operária?

Além desta breve introdução e das considerações finais, este ensaio está estruturado em seis seções. Inicialmente, assinalamos a resposta majoritária do movimento sindical brasileiro, na atualidade, à questão aqui proposta - se produtividade e saúde são ou não compatíveis. Nas duas seções seguintes, recuamos um ponto no tempo de modo a desenvolver a análise de algumas obras de perspectiva marxista com base na experiência histórica do enfrentamento do capital pelos trabalhadores, especialmente na Itália nos anos 1967-1978, para pensar, respectivamente, a questão capitalismo e saúde e a relação entre ciência e experiência. Na quarta seção, discutimos as contribuições e os limites do chamado Modelo Operário Italiano (MOI) de luta pela saúde. A seguir, recuperamos o sentido de classe trabalhadora ao considerar o legado do MOI de luta pela saúde no Brasil no que se refere à relação ciência e experiência operária. Na sexta seção, a título de ilustração, trazemos duas recentes experiências de resistência aberta dos trabalhadores brasileiros à exploração capitalista relacionada à luta pela saúde para, em seguida, nas considerações finais, esboçar uma resposta à questão proposta inicialmente. Tentaremos, ao seguir este caminho, situar questões para o campo da Saúde do Trabalhador, apontando também alguns desafios para retomar e avançar as bases de uma perspectiva de saúde como luta da classe trabalhadora no âmbito da produção de conhecimento e das ações em saúde.

\section{Produtividade do trabalho e saúde do trabalhador}

Desde o final da década de 1980 o movimento sindical, em seus setores mais dinâmicos e organizados, adotou, frente aos conflitos entre capital e trabalho, uma posição em que ninguém perde, todos ganham ${ }^{1}$. É o que comumente se denomina posição de "ganha-ganha" (Win-Win). Isso se traduz na busca dos sindicatos em preservar empregos com benefícios nos contratos de trabalho e compromissos com a melhoria da competitividade e da eficiência das empresas ${ }^{2}$. Em decorrência, a resposta à questão proposta é que "produtividade e saúde" são compatíveis. Entendemos que a defesa dessa política oculta a aceitação da dominação de classe e a exploração da força de trabalho pelo capital, sendo expressão do enraizamento da ideologia burguesa no movimento sindical.

A relação entre produtividade e saúde foi um dos temas do IV Congresso dos Metalúrgicos do ABC Os metalúrgicos do $\mathrm{ABC}$ e a reforma sindical ${ }^{3}$ - que resume a linha geral seguida até hoje pela maioria absoluta das centrais sindicais no país, com exceção da Intersindical (Instrumento de luta e organização da classe trabalhadora), da CSP-Conlutas (Central Sindical e Popular) e da Intersindical Central da Classe Trabalhadora.

Inicialmente, a relação entre "produtividade e saúde" foi então vista como compatível, ainda que marcada por ambiguidade. A ambiguidade está expressa no seguinte trecho do artigo de convocação para o evento que merece ser transcrito:

\footnotetext{
Saúde e produtividade, por serem temas opostos, vão representar um grande desafio para os metalúrgicos do ABC. Estabelecer e contratar os índices de produtividade que as empresas necessitam para serem competitivas, devem combinar com saúde e vida dos trabalhadores e também com mais e melhores postos de trabalho ${ }^{4}$. (p. 3)
}

O tópico "Saúde e Competitividade: desafio para o movimento sindical", constante das Resoluções do IV Congresso dos metalúrgicos do $\mathrm{ABC}^{3}$, supera aquela ambiguidade inicial para assumir, nos próprios termos da formulação do tópico, o desafio de compatibilizar saúde com aumento da produtividade, agora incluída na competitividade empresarial dentro do ramo automobilístico numa conjuntura de 
"globalização" da economia. A pressão, o adensamento e o ritmo de trabalho presentes nas empresas são entendidos como "fatores organizacionais do trabalho" a ser alterados mediante o questionamento do "grau de saturação do trabalhador", ou seja, da produtividade de trabalho nos diferentes postos de trabalho, de modo a compatibilizar prevenção de acidentes e doenças de trabalho com a geração de emprego. Sabemos bem o quanto essa pretensão era retórica ou pelo menos ilusória diante da alta rotatividade da mão de obra contratada por tempo determinado pelas empresas ao longo dos ciclos econômicos. Destinava-se na verdade a justificar a necessidade do Comitê Sindical de Empresa (CSE) como instrumento para o recrutamento de ativistas e o controle dos associados nos locais de trabalho.

Tal posição era resultado da "verdadeira obsessão" com o crescimento econômico e a geração de emprego que caracteriza o sindicato dos metalúrgicos do ABC desde os idos de 1992 quando participou, com os capitalistas do ramo automotivo e com apoio do governo federal, da criação da Câmara Setorial da Indústria Automobilística e a subsequente definição do chamado regime automotivo, em 1995, no governo de Fernando Henrique Cardoso.

Apenas a título de observação, a perspectiva de conciliar produtividade e saúde não se resume ao âmbito sindical; orienta inclusive algumas das análises da intensificação do trabalho a exemplo de Fairris e Brenner ${ }^{5}$.

\section{Capitalismo e saúde: análise de algumas obras}

Teremos de recuar um pouco mais no tempo para darmos conta do quadro geral de defensiva em que o movimento operário, em seus setores mais dinâmicos e organizados, se encontra ante o capital, em escala mundial a partir da década de $1980^{6}$; e destacar como enfraqueceu, no Brasil, sua capacidade de lutar em defesa de seus interesses específicos desde o abandono da linha "classista" pela corrente que originou a Central Única dos Trabalhadores e, entre as lideranças de esquerda, da bandeira do socialismo e da teoria marxista nos idos de 1990.

Algumas obras importantes, escritas no contexto da recessão mundial de 1974, dão conta da incompatibilidade entre produção capitalista e saúde. A mais conhecida destas no campo da Saúde do Trabalhador é Medicina e política, em que se destaca o capítulo "O capital como fator patógeno", de Giovanni Berlinguer ${ }^{7}$. Compilação de escritos entre 1970 e 1972, às vésperas daquela crise na Itália e, de resto, na Europa e no mundo Ocidental, Berlinguer mostra nessa obra traduzida no Brasil em 1978 como, apesar do aumento secular da expectativa de vida desde meados do século XIX, observava-se, inclusive nos países com sistemas públicos de proteção social, uma tendência à queda da duração da vida "na medida em que os indivíduos estão diretamente envolvidos no processo de produção capitalista"7 (p. 61). Berlinguer ${ }^{7}$ (p. 69) retoma uma passagem de Marx em O capital:

O capital não somente ultrapassa os limites máxi-
mos morais do trabalho, mas também os limites pu-
ramente físicos. Usurpa o tempo necessário para o
crescimento, o desenvolvimento e a sã consciência
do corpo. Rouba o tempo necessário para consumir
ar livre e luz solar. Reduz o sono a tantas horas de
torpor, quantas se tornem indispensáveis para reani-
mar um organismo absolutamente esgotado

E conclui com uma metáfora interessante, na qual a exploração do trabalhador pelo capital e a destruição ambiental caminham de mãos dadas: o capital explora o trabalhador "encurtando a duração de sua vida, como um agricultor ganancioso obtém frutos maiores do solo, roubando a sua fertilidade"7 (p. 69).

Essa análise marxista é partilhada por Giulio Alfredo Maccacaro ${ }^{8}$ no ensaio "Carta al presidente del Colegio Médico", publicada em 1972 como parte do prefácio do livro A medicina do capital, de Jean-Claude Polack. Maccacaro é, ao lado de Giovanni Berlinguer e Franco Basaglia, uma das figuras importantes, como se diz no resumo desse ensaio publicado na revista Salud Colectiva da Universidad Nacional de Lanús ${ }^{8}$, que recolocou o papel da medicina (a medicina do capital, afirmava) e conseguiu conjugar a prática científica com um forte compromisso social expresso na luta dos operários da indústria química do grupo Montedison em Castellanza, Itália. Eis o que ele escreveu, aqui numa tradução livre:

\footnotetext{
Porém não se ensina nem tampouco se divulga, e portanto, pouco se sabe, que a vida média não se diferenciava segundo classes sociais até o início da Revolução Industrial; é quando a morte e a doença discriminam - cada vez com maior impacto e gravidade - dentro de uma mesma coletividade, entre ricos e pobres, entre a classe do capital e a do traba$\mathrm{lho}^{8}$. (p. 120)
}

Outra obra que pode ser citada é $O$ trabalho alienado, stress e doença coronariana, de Jon Garfield ${ }^{9}$. O autor, com base no conceito filosófico de alienação desenvolvido nos Manuscritos econômico-filosóficos de 1844, apoia-se no estudo Trabalho e capital monopolista, de Harry Braverman ${ }^{10}$, para afirmar que o capital "tem um interesse direto em regular e maximizar o ritmo e a carga de trabalho"9 (p. 165-166) cujo resultado é a perda da saúde por parte do trabalhador.

É importante ressalvar que nos Manuscritos econômico-filosóficos Marx ainda permanecia preso 
à herança hegeliana e não raciocinava, como posteriormente, em termos de exploração da força de trabalho. Entendendo-se, como faz Garfield, trabalho alienado como a perda do controle do trabalhador em relação ao produto do trabalho, ao processo de trabalho e aos demais trabalhadores, esse controle aparece como externo ao trabalhador, não como parte de uma luta em torno da relação entre trabalho necessário e trabalho excedente, portanto da mais-valia, ou seja, de exploração da força de trabalho ${ }^{11}$.

Para Garfield, o "controle externo do processo de trabalho" pelo capital não considera "as necessidades autodefinidas dos trabalhadores"9 (p. 166), sem situá-las ou entendê-las no âmbito da história. Ou seja, com as noções de "alienação" e "controle", o autor oferece uma explicação materialista mas ainda circunscrita ao materialismo mecânico, sem acolher a história, pois os trabalhadores são vistos como "impotentes”, obstruídos de enxergar suas necessidades reais.

Desse modo, o emprego dessas noções por Garfield constitui um obstáculo à produção de conhecimento, ao não observar concretamente as contradições reais e as resistências à exploração expressas no processo de trabalho, a mobilização do trabalhador durante a jornada de trabalho, as "manhas" ou astúcias produzidas pelos operários e as demais formas para trabalhar e, ao mesmo tempo, tentar driblar a gerência capitalista, inclusive pela autointensificação do trabalho. A mobilização do trabalhador assume diferentes sentidos, é um campo de luta, e não explicada em termos de ausência ou presença de controle.

A par das limitações teóricas apontadas na abordagem de Garfield, ele está preocupado em saber se é possível ao trabalhador adquirir o controle do processo de trabalho, uma possibilidade, afirma ele, que “deve ser considerada no contexto mais amplo do capitalismo avançado e da luta de classes contemporânea"9 (p. 172).

Para isso, assinala duas tentativas de resolução desse problema. A primeira procura alcançar a democratização no ambiente de trabalho, isto é, nas empresas, mediante a participação operária. O autor cita experimentos, como o "enriquecimento do trabalho”, que depois assumiriam forma generalizada na chamada Qualidade Total. A segunda, a luta de classes, embora não necessariamente revolucionária, coloca exigências mais radicais que transbordam o poder da gerência capitalista nas empresas e que, citando outro autor, Wachtel, poderiam constituir "uma forma embrionária de socialismo"9 (p. 174).

Observamos a limitação do autor em pensar o socialismo sob uma perspectiva reformista, ou seja, ao não colocar o problema da conquista do poder e, portanto, da revolução. Mas tal limitação é parte do pensamento de esquerda da época e, portanto, do que nós já denominamos de situação de defensiva com a qual se encontra o movimento operário ainda nos dias atuais.

\section{Ciência e experiência operária}

Expostas as considerações precedentes, como devemos pensar a relação ciência e experiência operária para o campo de conhecimento da saúde do trabalhador no momento atual?

Precisamos retomar a questão originalmente proposta sobre a relação entre produção capitalista e saúde, mas a façamos por meio da formulação esboçada por Marx ${ }^{12}$ nos Grundrisse: manuscritos econômicos de 1857-1858, de grande atualidade para nossa reflexão:

[O capital] traz à vida todas as forças da ciência e da natureza, bem como da combinação social e do intercâmbio social, para tornar a criação da riqueza (relativamente) independente do tempo de trabalho nela empregado. Por outro lado, ele quer medir essas gigantescas forças sociais assim criadas pelo tempo de trabalho e encerrá-los nos limites requeridos para conservar o valor já criado como valor ${ }^{12}$. (p. 589)

Em outros termos, numa apresentação mais sintética, a gigantesca riqueza gerada pela ciência e pela cooperação social continua a ser medida pela bitola estreita da mais-valia.

Deveríamos, nessa perspectiva, assumir a visão da ciência como sendo ideologicamente neutra, equidistante dos interesses de classe e passível, portanto, de ser controlada e seus usos socialmente orientados?

Para responder a essa questão lançaremos mão do artigo "Ciencia y experiencia obrera: la lucha por la salud en Italia”, de Asa Cristina Laurell ${ }^{13}$, trabalho tão importante quanto desconhecido pela maioria e esquecido por alguns dentro da área da medicina social e da saúde do trabalhador.

Inicialmente ela se pergunta a respeito do papel da ciência no que denomina "projeto histórico da classe operária”13 (p. 63). Tal como no pensamento de Garfiled $^{9}$, observamos também nessa autora uma abordagem de cunho filosófico, marcada pelo uso de conceitos como essência, alienação e projeto, cuja limitação para a compreensão mais aprofundada do processo histórico real merece ser reiterada. Ainda assim, trata-se da abordagem mais ampla e circunstanciada da experiência mais avançada do movimento operário mundial no que diz respeito à saúde do trabalhador, legado do qual devemos nos apropriar criticamente. 
Pois bem, quanto ao conteúdo e à orientação da ciência, Laurell ${ }^{13}$ constata que, no debate da esquerda podem-se delinear, do ponto de vista conceitual-político, três posições. A primeira confere à ciência e sua aplicação tecnológica um sentido universal e neutro diante do desenvolvimento das forças produtivas sob o capitalismo. O problema seria como realizar o controle social e os usos sociais da ciência.

A segunda posição é a de que ciência tem um conteúdo classista na medida em que "responde ao esforço sistemático de resolver problemas correspondentes à realização dos interesses da classe dominante e apenas de modo subordinado ao das classes dominadas"13 (p. 63). A autora ressalta, com base em Braverman ${ }^{10}$, que na aplicação do conhecimento científico as opções tecnológicas escolhidas são as que garantem a dominação de classe da burguesia sobre o proletariado. Vale retomar Marx ${ }^{12}$ nos Grundrisse: sob o capitalismo, a ciência se defronta com o trabalhador sob a forma de capital fixo.

A terceira posição situa a ciência e a tecnologia como processos que aumentam a desigualdade social e destroem o patrimônio natural da humanidade. Em vez de reorientar o desenvolvimento científico, diz a autora, essa posição se opõe, de modo sistemático, à ciência. Podemos apontar a semelhança dessa posição evasiva com o chamado pensamento pós-moderno.

Entretanto, em nenhum momento Laurell ${ }^{13}$ abandona o nível abstrato da reflexão para identificar qual é a base que, no capitalismo, permite a autonomização da ciência diante dos interesses dominados e sua incorporação da subordinação aos dominantes. Essa foi, aliás, a contribuição dos estudos de Charles Bettelheim sobre as sociedades de transição, seja do capitalismo para o socialismo, seja o contrário. É particularmente notável em A revolução cultural e a organização industrial na China ${ }^{14}$. Neste ao mencionar "a luta dos trabalhadores pelo domínio coletivo das ciências e das técnicas", como de uma "decisiva importância” para a transição, Bettelheim ${ }^{14}$ (p. 106) lembra que em todas as sociedades divididas em classes há a separação social entre teoria e prática. E no capitalismo:

Essa separação é especialmente concretizada pela acumulação de conhecimentos teóricos científicos e técnicos, de um lado, e de conhecimentos "práticos", de outro. Os primeiros tomam a forma das ciências e técnicas das quais os cientistas, engenheiros e técnicos são tidos como detentores exclusivos, enquanto que os conhecimentos práticos são reduzidos a serem simples detalhes ou simples habilidades manuais mais ou menos rotineiras ${ }^{14}$. (p. 106)

Em decorrência disso, as ciências permanecem separadas dos problemas concretos enfrentados pela população trabalhadora. Teria a separação entre teoria e prática sido superada na experiência italiana dos anos 1967 a 1969 no interior da qual se configura o chamado "modelo operário de luta pela saúde" ou de conhecimento e ação no campo da Saúde do Trabalhador?

De acordo com Laurell ${ }^{13}$, nesse processo "a experiência operária vai sendo incorporada na construção de um conhecimento da realidade passível de forjar uma estratégia para sua transformação.” (p. 64). Contudo, o salto para a "sistematização e generalização", ou seja, a elaboração de uma teoria capaz de ultrapassar o movimento operário em seus aspectos particulares e concretos requer "postular a necessidade de um processo científico como parte de um projeto de classe"13 (p. 64).

Estamos aqui diante do chamado marxismo tal como se desenvolveu a partir da social-democracia alemã orientada por Karl Kautsky. Essa concepção foi examinada criticamente por Göran Therborn ${ }^{15}$ em "The working class and the birth of marxism". Neste trabalho, Therborn segue o caminho trilhado por David Riazanov ${ }^{16}$ nas conferências realizadas na Academia Comunista de Moscou, em 1923. Uma vez que a união da teoria do materialismo histórico e do movimento proletário é a base do marxismo, trata-se de examinar como se estabeleceu essa relação. Therborn ${ }^{15}$ menciona a passagem "famosa" de Kautsky que define o papel da intelectualidade na formação da consciência socialista do proletariado, ainda mais famosa porquanto Lênin ${ }^{17}$ baseou-se nela para a crítica aos economicistas russos em 1902.

Façamos a transcrição da "famosa" passagem de Kautsky, a propósito do projeto de programa do partido social-democrata austríaco de 1902, contida na brochura Que Fazer? Problemas candentes do nosso movimento, de Lênin ${ }^{17}$. Nesse programa, as ideias apresentadas faziam acreditar que

\footnotetext{
a consciência socialista aparece como resultado necessário e direto da luta de classe do proletariado. Mas isso é completamente falso. [...] O socialismo e a luta de classes surgem um ao lado do outro; surgem de premissas diferentes. A consciência socialista moderna não pode surgir senão na base de profundos conhecimentos científicos. [...] Mas o portador da ciência não é o proletariado, mas a intelectualidade burguesa (sublinhado por KK): foi do cérebro de alguns membros desta camada que surgiu o socialismo moderno e foram eles que o transmitiram aos proletários intelectualmente mais desenvolvidos, os quais, por sua vez o introduzem na luta de classe do proletariado onde as condições o permitem. Deste modo, a consciência socialista é algo introduzido de fora na luta de classe do proletariado e não algo que surgiu espontaneamente [...] no seu seio"17. (p. 107)
}

Apesar de concordar que a consciência socialista não surge espontaneamente, Therborn ${ }^{15}$ observa que 
Kautsky comete o equívoco de falar em intelectualidade burguesa, quando se tratou, no caso das origens sociais de Marx e Engels, de uma intelectualidade pequeno-burguesa radicalizada, a ala esquerda dos “jovens hegelianos"; Kautsky fica em silêncio absoluto, principalmente, sobre o aprendizado que eles tiveram com o movimento operário. Aprenderam, diz Therborn ${ }^{15}$, a materialidade do mundo social real e a luta de classes travada pelo proletariado. Nas palavras desse autor:

Os fundadores do socialismo científico tiveram que aprender duas coisas com o proletariado. Primeiro, eles tiveram que aprender a materialidade concreta do mundo social real, além de todos os problemas de teologia ou do estado racional. Segundo, eles tiveram que aprender a luta de classe, aprender a ver o proletariado não apenas como a classe mais sofrida como viam os socialistas utópicos - mas descobrir "o operário orgulhoso, ameaçador e revolucionário".

Therborn ${ }^{15}$ se refere ao papel da teoria em esclarecer os interesses do proletariado no desenvolvimento dos antagonismos de classe, mas - cabe acrescentar - a importância da própria luta do proletariado para o desenvolvimento da teoria. A esse respeito, sempre se deve lembrar como a experiência da Comuna de Paris, em 1871, na qual a própria liderança revolucionária aprendeu na prática a avançar na conquista do poder, a saber, a quebrar e substituir a máquina do Estado burguês ou, como escreveram Marx e Engels, a implantar a ditadura do proletariado como forma política da transição ao socialismo.

\section{O Modelo Operário Italiano de luta pela saúde}

Entretanto, na Itália dos anos 1967-1968 e principalmente no "outono quente" de 1969, a espontaneidade das massas operárias não era a expressão do início de um movimento socialista como fora no começo do século na Rússia. Pelo contrário, constituía uma massa que fora deixada de lado pelas direções sindicais das três grandes correntes partidárias (comunistas, socialistas, democratas-cristãos) durante o período que se seguiu à reconstrução econômica do pós-guerra. Era a resposta das grandes massas operárias - 5 milhões em 1967, 7,5 milhões em 1968 informa Laurell ${ }^{13}$ - que estavam submetidas, ao longo das duas décadas anteriores, à intensa exploração nas fábricas metalúrgicas e mecânicas e à insegurança no trabalho marcada pela alta rotatividade combinada com um grande aumento de produtividade do trabalho. Uma resposta aparentemente espontânea, quando na verdade era em muitos casos, como pertinentemente observa Perry Anderson ${ }^{18}$ no ensaio "Uma esquerda invertebrada: a herança desperdiçada da Itália”, o resultado da atividade dos jovens radicais, alguns vinculados ao Partido Socialista, nas fábricas, num encontro entre intelectuais e operários denominado na época de operaísmo, uma corrente anticapitalista que gerou "uma sucessão de jornais seminais, ainda que de vida curta - Quaderni rosso, Classe operaia, Gatto selvaggio, Contropiano"18 (p. 6).

As características fundamentais dessas lutas estão definidas, afirma Laurell ${ }^{13}$, pelo seu ponto de partida e base nos locais de trabalho enquanto revoltas contra a gestão e organização capitalista do trabalho que se generalizam sob formas de democracia direta como a assembleia, os delegados e os conselhos de fábricas.

Vale citar as estatísticas desse impressionante movimento registradas no livro organizado por Oddone, Marri, Gloria, Briante, Chiattella e $\mathrm{Re}^{19}$ : 10 mil conselhos de fábrica com 97 mil delegados representando 2,5 milhões de trabalhadores em 1972 e 32 mil conselhos com 206 mil delegados representando 5,2 milhões de trabalhadores em 1977. A partir disso redundará a constituição de sindicatos únicos como os do ramo metal-mecânico e do químico e os pactos federativos entre as três centrais sindicais em 1972.

Quanto à saúde dos trabalhadores, torna-se um tema central do movimento operário na medida em que está centrado em torno da organização capitalista do trabalho. A importância estratégica do tema expressa-se na lei conhecida como Estatuto dos Trabalhadores de 1970, que favorece a realização de milhares de estudos destinados a concretizar o direito à transformação da organização do trabalho e sua ratificação na Conferência sobre a proteção da saúde nos centros de trabalho, realizada em Rimini em 1972. As resoluções dessa conferência incorporam, do ponto de vista sindical, as orientações advindas da experiência operária iniciada na Fiat Mirafiori sob a coordenação de Oddone ${ }^{19}$ : a saúde não se vende, sendo imperioso conquistar mudanças reais no ambiente e na organização do trabalho; a iniciativa sindical deve basear-se na ação reivindicatória que se sustenta nos locais de trabalho organizados nos grupos homogêneos, nos delegados, nos conselhos de fábrica. A não delegação e a ação operária "na primeira pessoa” do plural são princípios metodológicos definidos como centrais. A passagem da luta pela saúde na fábrica à sociedade expressa-se na proposta da Reforma Sanitária.

Vale enfatizar: é na experiência das lutas do chamado "outono quente" que essa experiência pode generalizar-se para superar, de um lado, a divisão ideológica do movimento operário italiano e estabelecer, de outro, uma posição política a partir da qual poderiam avançar conquistas de um ponto de 
vista de classe. É a própria Laurell ${ }^{13}$ que pontua esse "salto" de um movimento de baixo para cima, da base para as direções sindicais e da luta econômica para a política.

Um salto incompleto e frustrado por razões internas ao próprio movimento operário que ajuda a compreender como a burguesia consegue reverter de modo tão profundo no final dos anos 1970, produzindo a derrota da "ofensiva operária anticapitalista mais importante da Europa de pós-guerra”13 (p. 75).

Entretanto a autora ${ }^{13}$ não examina as razões de ser desse processo que remetem a uma herança desperdiçada, como afirma Anderson ${ }^{18}$. Ela aponta uma contradição entre a lógica sindical essencialmente pautada pela negociação e a mobilização operária, anticapitalista e tendente a pôr em questão o controle sobre o processo de trabalho na empresa, cuja resolução teria de ser política, responsabilidade a ser assumida pelo partido operário que coloca a questão do poder. Mas, eis aí o problema não resolvido: esse partido (entenda-se, o Partido Comunista Italiano PCI) estava imbuído da estratégia do compromisso histórico com a democracia cristã (comunismo e cristianismo) e a "democratização progressiva" do Estado burguês; em outros termos, esta anotação é de nossa autoria, não de Laurell ${ }^{13}$, o partido não colocava em questão o poder. Mas Laurell ${ }^{13}$ abrevia um debate excessivamente complexo e importante e o situa de modo dicotômico ao contrapor o compromisso histórico à ação armada da esquerda, afirmando "que ambos se mostram como erros políticos, talvez complementares, no transcorrer do tempo e dos acontecimentos"13 (p. 81).

Nesse sentido, importa registrar que, ao surgir uma oposição de esquerda no interior do PCI (o chamado grupo Il Manifesto, de Rossana Rossanda e outros) com uma influência política mais ampla do que os "operaisti”, a direção do partido não perdeu tempo em expulsá-la, tomando como pretexto a condenação da invasão da Tchecoslováquia pela então União das Repúblicas Socialistas Soviéticas (URSS) em 1968. Não entraremos no mérito desse processo examinado com bastante profundidade por Anderson ${ }^{18}$.

A derrota do movimento operário pode ser entendida, portanto, como a derrota de um "ensaio radical” que obrigou a direção dos partidos com influência na classe a questionar amplamente a gestão capitalista nas empresas. Mas a ofensiva burguesa, que começa a delinear-se nos anos 1974-1975, solapa as experiências acumuladas - deixando patente que qualquer conquista parcial, como o Estatuto dos Trabalhadores, será sempre parcial e, mais ainda, provisória - e produz como consequência uma retomada da influência da burocracia sindical na nova fase marcada pelo distanciamento entre o aparelho sindical e suas bases ${ }^{13}$.

É então que o MOI de luta pela saúde mostrou também seus limites. O modelo, como comenta pertinentemente Laurell ${ }^{13}$, estruturava-se num enfoque médico dominante por meio dos "grupos de riscos", o que reduz a importância metodológica da experiência operária.

As características da gestão, organização e divisão do trabalho capitalista estão envolvidas na produtividade e, para o entendimento do processo saúde-doença dos trabalhadores, segundo o pesquisador equatoriano Jaime Breilh ${ }^{20}$ (p. 98), tais características não são apreendidas pela noção de "risco" ou "fatores de riscos", "porque constitui um processo determinante de caráter necessário e permanente e não um simples perigo contingente ou provável”.

A partir do final dos anos 1970, o enfoque nos riscos foi privilegiado para restringir a ação àqueles grupos de riscos e danos físico-químicos que podiam ser negociados ponto a ponto nas empresas, inclusive com o retorno à monetização do risco, abandonando o ponto de partida da luta em torno da gestão e organização capitalista do trabalho.

A ofensiva capitalista encontra amparo, portanto, na antiga lógica sindical com a qual se volta a negociar a saúde. Nas palavras de Laurell ${ }^{13}$, contrapõem-se "o emprego à saúde, o salário à saúde, a produtividade à saúde”.

\section{O legado do MOI no Brasil: em torno da ciência e experiência}

O MOI de luta pela saúde influenciou várias iniciativas na saúde do trabalhador no Brasil: no âmbito da articulação sindical em saúde por meio da criação da Comissão Intersindical de Saúde do Trabalhador (Cisat), em 1979, posteriormente Departamento Intersindical de Estudos de Saúde e dos Ambientes de Trabalho (Diesat), em $1980^{21,22}$ e do Instituto Nacional de Saúde no Trabalho da Central Única dos Trabalhadores (INST/CUT), em 1990, apesar de as ações deste último em relação às do Diesat representar um recuo para o enfoque nos riscos, inclusive admitir o uso controlado de agentes químicos como o benzeno, substância comprovadamente cancerígena sem, portanto, a possibilidade de uma exposição segura $^{23}$. Em termos da política institucional, a influência do MOI pode ser observada na incorporação à legislação do Mapa de Riscos pela Comissão Interna de Prevenção de Acidentes (Cipa) ${ }^{24}$, bem como do princípio da participação dos trabalhadores e de suas organizações, especialmente as sindicais, nas ações de Vigilância em Saúde do Trabalhador (Visat) ${ }^{25}$. 
No campo científico, o MOI representa uma das bases constitutivas da área de conhecimentos e práticas em saúde do trabalhador no âmbito da saúde coletiva. Na área de saúde do trabalhador no Brasil, a análise do MOI de luta pela saúde tem oferecido especial atenção à figura do médico e psicólogo Ivar Oddone (entre outros colaboradores) ${ }^{26}$.

Oddone constitui um dos pilares da contribuição da Clínica da Atividade, proposta por Yves $\mathrm{Clot}^{27}$. Do ponto de vista metodológico, os esforços de Clot estão dirigidos para construção de instrumentos de ação pelos próprios trabalhadores e que fortaleçam o poder de agir dos coletivos de trabalho na direção das mudanças de seus locais de trabalho. Ou seja, a preocupação da Clínica da Atividade é proporcionar instrumentos de análise das situações de trabalho que ampliam o poder de agir dos trabalhadores, entendidos como os reais protagonistas das transformações que somente são efetivas quando resultam de sua própria ação.

A vertente de Oddone gerou a Comunidade Científica Ampliada (CCA), posteriormente alterada criticamente para Comunidade Ampliada de Pesquisa ${ }^{28}$ com base no chamado Dispositivo Dinâmico de Três Polos (DD3P) desenvolvido por Schwartz ${ }^{29}$. Nas três propostas, os conhecimentos produzidos por diferentes disciplinas científicas, de um lado, e os saberes da experiência dos trabalhadores, de outro, recorrem, para sua efetivação, à mediação de um terceiro polo: na CCA, trata-se da "consciência de classe", embora genérica, sem explicitação ou definição, estava interiorizada e era comum a todos os participantes; no DD3P e na CAP, a mediação é do polo da "ética" compreendida no quadro de uma "filosofia da humanidade", afastando-se da "consciência de classe".

Os três dispositivos introduzem na relação ciência e experiência a mediação de um terceiro polo, um ente externo às relações em que os dois, ciência e experiência, estão imersos, ou seja, o processo histórico. Laurell ${ }^{13}$ apontou os problemas na proposta de Oddone em considerar a experiência (do grupo homogêneo) como expressão direta da experiência da classe. No entanto, a ergologia, com o DD3P e a CAP, direcionou esses dispositivos para outro problema: a construção do conhecimento imediato entre empregados, técnicos e gestores, um enfoque diferente das lições da experiência italiana assentada na crítica à gestão e organização capitalista do trabalho.

Além de questionarmos a possibilidade de um conhecimento partilhado entre os trabalhadores, os técnicos e os gestores ${ }^{30}$, entendemos experiência operária não como resultado do conhecimento imediato e direto (ou "empirismo") de sua atividade, mas como aquela produzida na relação entre o experimento e as teorias (científicas ou não) no enfrentamento concreto à exploração capitalista do trabalho e à dominação política e ideológica, ou seja, no âmbito da luta de classes em seu sentido amplo. Experiência operária é experiência de luta, por isso é importante identificar e entender as relações de classe nas quais estão envolvidas, quais os interesses de classe que estão em luta, contra o que lutam os trabalhadores, como lutam e pelo que lutam; portanto, experiência de luta, não redutível apenas ao que dizem os trabalhadores, técnicos e gestores envolvidos numa empresa ou instituição.

As experiências dos trabalhadores produzidas no enfrentamento à gestão e à organização capitalista do trabalho são múltiplas, não apenas são convergentes ou complementares, como também, por vezes, são contraditórias entre si; logo, não se trata apenas de sistematizá-las. Ou seja, o coletivo de trabalhadores e pesquisadores/profissionais de saúde não se deve limitar a sistematizar as experiências em termos dos efeitos das práticas mais imediatas dos trabalhadores, mas fazê-las após distinguir seus diferentes e contraditórios aspectos, sem se furtar aos desafios de estabelecer a conexão lógica e histórica com as determinações mais profundas do processo de produção e saúde nas condições concretas do desenvolvimento capitalista.

\section{Capitalismo e saúde no caso do Brasil}

Como dissemos no início deste ensaio, desde a virada dos 1980 em diante difundiram-se no Brasil práticas de gestão da produção e da força de trabalho pelo capital, como a Participação nos Lucros e Resultados (PLR) e a flexibilização da jornada de trabalho por meio do "banco de horas", com objetivo de aumentar a produtividade, prolongar a jornada e intensificar o trabalho.

Essas práticas de gestão da exploração da força de trabalho pelo capital, difundidas nos processos de trabalho de vários ramos econômicos do setor privado ou público, estão na determinação de variados problemas e agravos à saúde dos trabalhadores (acidentes de trabalho, lesões por esforços repetitivos, doenças cardiovasculares, problemas psíquicos, queixas de mal-estar e sofrimento difuso) ${ }^{31}$.

Ao mesmo tempo, essas práticas de exploração são inseparáveis das múltiplas formas de resistência, veladas ou abertas, desenvolvidas pelos trabalhadores. Citamos dois momentos em que essa resistência se manifestou abertamente, observada em duas greves dos operários da Volkswagen do Paraná: na primeira, em maio de 2004, segundo o depoimento de um sindicalista, a greve 
teve como principal causa, não a PLR e o banco de horas, mas o ritmo intenso de trabalho. Os trabalhadores utilizaram a greve para ganhar um fôlego. [...] a pauta de negociação da greve foi apenas uma forma de dar caráter reivindicatório e palpável à direção da empresa. ${ }^{32}$ (p. 41)

É curioso que o sindicalista, ao mesmo tempo que admite o intenso ritmo de trabalho a que estão submetidos os trabalhadores - por isso os operários "utilizaram a greve para ganhar um fôlego" -, tenta defender as práticas (PLR e banco de horas) de administração por estresse, características do atual processo de intensificação do trabalho ${ }^{1}$.

Na segunda greve, em maio/junho de 2011, com duração de 37 dias, os trabalhadores questionaram as exigências de vinculação da PLR às metas de produção e à contratação de jornadas adicionais ao longo do ano. Segundo o presidente do Sindicato dos Metalúrgicos da grande Curitiba:

Não só o valor [da PLR] foi preponderante para que a proposta fosse rejeitada, mas também a posição da empresa em querer impor dias adicionais de produção ao trabalhador. A empresa não entende que aqui no Paraná, os trabalhadores têm uma consciência maior e sabe que esses dias adicionais poderão resultar em doenças de trabalho e até algumas sequelas graves. ${ }^{33}$

A mobilização operária, mais uma vez, confrontou a gestão e organização capitalista do trabalho, embora o resultado da greve não tenha conseguido desvincular a PLR das metas de produção e das jornadas adicionais de trabalho. A gestão capitalista atua sistematicamente para deslocar o questionamento operário contra as exigências de trabalho suplementar, subjacente às práticas de prolongamento, intensificação e aumento da produtividade do trabalho, para a negociação sobre o valor desse suplemento, geralmente traduzido em acréscimos na remuneração das horas extras, bônus da PLR ou prêmios a título de produtividade.

Ou seja, a monetização do risco à saúde subjacente na gestão e na organização capitalista do trabalho posta em questão pelos operários, como vimos no caso italiano, é reiterada nas recentes experiências de luta no Brasil. Guardadas as devidas proporções, assim como na experiência italiana, entre nós, na atualidade, as ideias mais avançadas no que concerne à relação trabalho-saúde, ainda que em estado prático, emergem da experiência de luta dos trabalhadores de base, e não das cúpulas sindicais dos setores majoritários do sindicalismo no país. Entre os sentidos dessas lutas, coletivos de trabalhadores reiteram, na expressão consagrada pelo MOI: "A saúde não se vende, nem se delega, se defende" ${ }^{13}$. Além de orientação para a ação reivindicativa e política dos trabalhadores emanada de suas experiências de lutas, essa consigna criticou e continua a criticar a concepção da medicina dominante e trouxe elementos para a mudança de abordagem teórica do campo científico das relações trabalho-saúde: retira a saúde da esfera mercantil da força de trabalho presente na relação capital-trabalho, ou seja, não mais como parte negociável da mercadoria força de trabalho, e sim como qualidade não renunciável da vida humana, como se depreende especificamente da primeira parte da consigna ("A saúde não se vende") ${ }^{13}$, comumente traduzida como direito à saúde. Mas a força de trabalho é inseparável da pessoa do trabalhador. Então, como excluir a saúde da esfera mercantil mantendo a força de trabalho como mercadoria negociada e consumida no processo de produção capitalista?

\section{Considerações finais}

A questão anterior nos conduz de volta à questão proposta inicialmente: pode haver compatibilidade entre produção capitalista e saúde? Após a digressão que desenvolvemos da análise de algumas obras de perspectiva marxista à experiência histórica do enfrentamento do capital pelos trabalhadores na Itália nos anos 1967-1978 e de algumas observações sobre o caso brasileiro, está claro que a resposta não tem um sentido conclusivo, e sim aponta a necessidade de retomar a problemática da relação ciência e experiência na luta pela saúde e a emancipação da ordem social capitalista.

Ao efetivar o consumo produtivo da força de trabalho, a exploração capitalista realiza o consumo das forças físicas, psíquicas e intelectuais do trabalhador, processo que produz desgaste, sofrimento e danos à saúde. A tendência dominante é imposta pelo capital, que se expressa nos perfis de morbimortalidade das classes trabalhadoras, registrados em diversos estudos. Mas essa tendência pode ser refreada pela luta de classes, enraizada na resistência dos trabalhadores à exploração. Isso nos conduz a enfatizar a concepção de saúde como luta da própria classe trabalhadora e não delegada a outrem, inclusive aos técnicos, profissionais de saúde e gestores das empresas ou do Estado, um sentido compreendido na segunda parte da expressão do MOI, "a saúde não se delega, se defende" ${ }^{13}$, mas quase despercebido, quando não ocultado, e pouco desenvolvido do ponto de vista da produção de conhecimento em saúde. Mais precisamente, saúde como luta da classe trabalhadora dotada de independência política em relação às demais classes sociais e ao Estado.

Esses dois sentidos, do direito à saúde e da saúde como luta da classe trabalhadora, estão unidos na mesma expressão, para nós, uma unidade sob a 
orientação da última, pois, enquanto a sociedade permanecer fundamentada na exploração capitalista e cindida em classes sociais, as conquistas sociais, inclusive a do direito à saúde, são parciais, limitadas e provisórias, isto é, passíveis de reversão.

Trata-se de articular o enfrentamento aos problemas e danos imediatos à saúde dos trabalhadores na direção da luta pela emancipação da ordem social burguesa; portanto, contribuir para retomar e avançar as bases de uma perspectiva de classe dos trabalhadores no âmbito da produção de conhecimento e das ações em saúde.

Cabe ainda perguntar: qual a importância que a ciência pode desempenhar nessa luta? A nosso ver, uma resposta não científica a essa última questão, com uma mirada mais abrangente, é apresentada por Galileu Galilei, personagem de Bertolt Brecht ${ }^{34}$, citada na epígrafe deste artigo.

\section{Contribuições de autoria}

Os autores contribuíram igualmente no desenvolvimento deste ensaio.

\section{Referências}

1. Pina JA, Stotz EN. Intensificação do trabalho e saúde dos trabalhadores: um estudo na Mercedes Benz do Brasil, São Bernardo do Campo, São Paulo. Saúde Soc. 2015;24(3):826-40.

2. Galvão A. A contribuição do debate sobre a revitalização sindical para a análise do sindicalismo brasileiro. Crítica marxista. 2014;38:103-17.

3. Sindicato dos Metalúrgicos do ABC. $4^{\circ}$ Congresso Os Metalúrgicos do ABC e a Reforma Sindical. Caderno de Resoluções; 2003 jun 26-27 [Internet]. São Bernardo do Campo: ABC Metalúrgicos; 2003 [Citado em 2016 nov 4]. Disponível em: http:// www.smabc.org.br/conteudo/doc/Congresso2004. pdf

4. Sindicato dos Metalúrgicos do ABC. Comissão de Saúde, Condições de Trabalho e Meio Ambiente. Saúde é tema do congresso. Tribuna Metalúrgica [Internet]. 2003 jul 3, 1667:3 [Citado em 2016 nov 4]. Disponível em: http://www.smabc.org.br/ Interag/tribuna_pdf/160806119.pdf

5. Fairris D, Brenner M. Workplace transformation and the rise in cumulative trauma disorders: Is there a connection? J Labor Res. 2001;22(1):15-28.

6. Meyer V. O Estado capitalista de volta às origens? (Uma abordagem crítica ao estado contemporâneo). Sitientibus [Internet]. 1999;21:68-87 [Citado em 2016 nov 4]. Disponível em: http://www2.uefs.br/ sitientibus/pdf/21/o_estado_capitalista.pdf

7. Berlinguer G. Medicina e política. São Paulo: Hucitec; 1978. p. 61; p. 69.

8. Maccacaro GA. Carta al presidente del Colegio Médico. Salud Colect. 2014;10(1):117-36.

9. Garfield J. O trabalho alienado, stress e doença coronariana. In: Nines ED. Medicina social: aspectos teóricos e históricos. São Paulo: Global; 1983. p. 165-74.

10. Braverman H. Trabalho e capital monopolista: a degradação do trabalho no século XX. Rio de Janeiro: Zahar; 1974.
11. Marx K. O capital: crítica da economia política. Livro I, T I. São Paulo: Abril Cultural; 1984.

12. Marx K. Grundrisse: manuscritos econômicos de 1857-1858: esboços da crítica da economia política. São Paulo: Boitempo; Rio de Janeiro: Ed. UFRJ; 2011. p. 589.

13. Laurell AC. Ciencia y experiencia obrera: la lucha por la salud en Italia [Internet]. Cuadernos polít. 1984;41:63-83 [Citado em 2016 nov 4]. Disponível em: http://www.cuadernospoliticos. unam.mx/cuadernos/contenido/CP.41/ CP41.6AnaCristinaLaurell.pdf

14. Bettelheim C. A revolução cultural e a organização industrial na China. Rio de Janeiro: Graal; 1979. p. 106.

15. Therborn G. The working class and the birth of marxism. New left ver [Internet]. 1973;I/79 [Citado em 2016 nov 4]. Disponível em: https:// newleftreview.org/I/79/goran-therborn-the-workingclass-and-the-birth-of-marxism

16. Riazanov D. Marx-Engels e a história do movimento operário. São Paulo: Global; 1983.

17. Lênin VU. Que fazer? Problemas candentes do nosso movimento. Obras escolhidas em três tomos. Tomo 1. 2. ed. Lisboa: Avante!; 1981. p. 107.

18. Anderson P. Uma esquerda invertebrada: a herança desperdiçada da Itália [Internet]. Vírus: Rev polít ideias. 2010;9:4-21 [Citado em 2016 nov 04]. Disponível em: http://www.revistavirus.net/media/ virus9.pdf

19. Oddone I, Marri G, Gloria S, Briante G, Chiattella M, Re A. Ambiente de trabalho: a luta dos trabalhadores pela saúde. São Paulo: Hucitec; 1986. p. 98.

20. Breilh J. Nuevos conceptos y técnicas de investigación. Guia pedagógica para un taller de metodología. Quito: CEAS; 1994.

21. Ribeiro HP, Lacaz FAC. De que adoecem e morrem os trabalhadores. São Paulo: Diesat; Imesp; 1984. 
22. Rebouças AJA, coordenador. Insalubridade: morte lenta no trabalho. São Paulo: Oboré; 1989.

23. Lacaz FAC. Saúde do trabalhador: um estudo sobre as formações discursivas da academia, dos serviços e do movimento sindical [tese]. Campinas: Unicamp; 1996.

24. Brasil. Ministério do Trabalho e Emprego. Portaria 25, de 29 de dezembro de 1994, Aprova o texto da Norma Regulamentadora 9: Riscos Ambientais. Diário Oficial da União, Brasília, DF, 30 dez 1994. Seção 1.

25. Brasil. Ministério da Saúde. Portaria 3.120, de $1^{\circ}$ de julho de 1998. Instrução normativa sobre ações de vigilância em saúde do trabalhador no SUS. Diário Oficial da União, Brasília, DF, 2 jul 1998. Seção I:36.

26. Muniz HP et al. Ivar Oddone e sua contribuição para o campo da Saúde do Trabalhador no Brasil. Rev bras saúde ocup. 2013;38(128):280-91.

27. Clot Y. Trabalho e poder de agir. Belo Horizonte: FabreFactum; 2010

28. Brito J, Athayde M. Trabalho, educação e saúde: o ponto de vista enigmático da atividade. Trab educ saúde (Online). 2003;1(2):239-66.
29. Schwartz Y. A comunidade científica ampliada e o regime de produção de saberes. Trab educação. 2000;7:38-46.

30. Stotz EN. A Participação como fator produtivo; o papel dos CCQ em empresa multinacional. Anais do V Encontro Nacional da Associação Brasileira de Estudos do Trabalho; 1997; Rio de Janeiro. Rio de Janeiro: Associação Brasileira de Estudos do Trabalho; 1997.

31. Pina JA, Stotz EN. Intensificação do trabalho e saúde do trabalhador: uma abordagem teórica. Rev bras saúde ocup. 2014;39(130):150-60.

32. Penkal RJ. Quando a lógica do capital contagia o movimento sindical: qualidade total e o sindicalismo moderado produtivo nos metalúrgicos da Grande Curitiba. [dissertação]. Curitiba: Universidade Federal do Paraná; 2005. p. 41.

33. Sindicato dos Metalúrgicos da Grande Curitiba. Sem acordo, metalúrgicos da Volkswagen mantêm greve pela PLR [Internet]. 31 maio 2011. [Citado em 2016 nov 4]. Disponível em: http://www.simec.com. $\mathrm{br} /$ ?area $=$ ler_noticia\&id $=1528 \&$ titulo $=$ sem-acordometalurgicos-da-volkswagen-mantem-greve-pela-plr

34. Brecht B. Vida de Galileu. Teatro completo, 6. Rio de Janeiro: Paz e Terra; 1991. p. 117. 